\title{
Evaluation of External Fixation Results in High-risk Older Patients with Intertrochanteric Femur Fractures
}

\author{
Musa Uğur Mermerkaya1, Fatih Karaaslan, Erkan Alkan², Mehmet Ayvaz ${ }^{3}$ and Şenol Bekmez ${ }^{4}$ \\ ${ }^{1}$ Bozok University Faculty of Medicine, Department of Orthopaedics and Traumatology, TR-66200, Yozgat, Turkey \\ ${ }^{2}$ Yalvaç State Hospital, Department of Orthopaedics and Traumatology, TR-32100, Isparta, Turkey \\ ${ }^{3}$ Hacettepe University Faculty of Medicine, Department of Orthopaedics and Traumatology, TR-06100, Ankara, Turkey \\ ${ }^{4}$ Sami Ulus Hospital, Department of Orthopaedics and Traumatology TR-06100, Ankara, Turkey
}

\begin{abstract}
Background: Intertrochanteric femur fractures are common in older people. In high-risk patients, especially American Society of Anesthesiologists (ASA) scores 3 and 4, surgery with internal fixation can cause excessive stresses. Therefore, external fixation is another option for treating these patients.

Objective: To evaluate the results and complications of external fixation in elderly patients with intertrochanteric fractures.

Methods: Twenty-six surgically high-risk patients with intertrochanteric fractures admitted to our clinic were treated with external fixation (January 2010- November 2011). Epidemiological and radiological data and also complications were recorded at each follow-up.

Results: No complications occurred in 13 patients. The remaining 13 patients had complications after surgery: Of the patients, 10 had implant failure ( 6 pin migration and 4 pin cut-out) and 3 had pin tract infections. Six patients who had implant failure (2 pin migration and 4 pin cut-out) underwent revision. Unrevised complicated patients (4 pin migration) and 2 of 3 patients with pin tract infections had malunion and shortening. High risk older patients with external fixation had a high complication and morbidity rate.
\end{abstract}

Conclusion: We do not recommend using pertrochanteric external fixators in high-risk patients due to the high revision rate and serious complications.

Keywords: Hip fracture; Trochanteric fracture; External fixation; High-risk patient; Osteoporosis; Pin migration

\section{Introduction}

Intertrochanteric femur fractures are common in older people. Advancing technology and treatment modalities have increased the life expectancies of males and females, so the incidence of these fractures is increasing [1]. Furthermore, with existing osteoporosis, bone fractures happen more easily with low-intensity trauma $[2,3]$. Given the high mortality and morbidity rates, it is important to treat these fractures surgically. In high-risk patients (American Society of Anesthesiologists (ASA) 3 and 4), however, surgery with internal fixation can cause excessive stress. Consequently, external fixation is another option for treating these high-risk patients [4,5]. External fixation [6-8], is superior to plate osteosynthesis due to shorter operation and hospitalization times, no need for blood transfusions, and earlier mobilization. We evaluated the results and complications of external fixation in elderly patients with stable and unstable intertrochanteric femur fractures.

\section{Patients and Methods}

Patients with intertrochanteric femur fractures were classified as surgically high-risk, if they had ASA scores of 3 or $4[9,10]$. Between January 2010 and November 2011, we treated 26 surgically high-risk patients with intertrochanteric femur fractures with closed reduction and external fixation under spinal anesthesia.

The fractures were classified as stable or unstable according to the modified Evans classification. In addition, the patients' demographic information (age, sex, and involved side) was recorded. The medical conditions increasing the surgical risk were evaluated and stabilized by the anesthesiologists and internists. Once their medical condition was stabilized, the patients were taken to the operation room and operated on under spinal anesthesia using a pertrochanteric external fixator (Orthofix pertrochanteric fixator), which is a specialized fixator for intertrochanteric femur fractures. Reduction was established by using fracture and traction table under floroscopy guidance. Two or 3 shanz screws $(6,5 \mathrm{~mm})$ were implanted for each proximal femoral region and femoral shaft.

No patient required transfusion during or after the operation. The operating time (minutes) and hospitalization duration (days) were recorded. The patients were given first-generation cephalosporins intravenously for $24 \mathrm{~h}$ postoperatively as antibiotic prophylaxis. Low-molecular-weight heparin was given subcutaneously every $12 \mathrm{~h}$ postoperatively for 3 weeks as venous thromboemboli prophylaxis.

The patients were mobilized with two crutches on the first postoperative day and allowed to bear partial weight. Full weightbearing mobilization was allowed $6 \sim 8$ weeks postoperatively if the radiological and clinical conditions were appropriate. Patients and their

*Corresponding author: Dr. Fatih Karaaslan, Bozok Universitesi Tıp Fakültei Ortopedi ve Travmatoloji Bolumu, Yozgat, Turkey, Tel: +90 35421270 60; E-mail: fkaraaslan@gmail.com

Received May 25, 2014 ; Accepted August 25, 2014; Published September 20, 2014

Citation: Mermerkaya MU, Karaaslan F, Alkan E, Ayvaz M, Bekmez Ş. Evaluation of External Fixation Results in High-risk Older Patients with Intertrochanteric Femur Fractures. Journal of Surgery [Jurnalul de chirurgie] 2014; 10(3): 237-239 DOI: $10.7438 / 1584-9341-10-3-7$

Copyright: () 2014 Mermerkaya MU, et al. This is an open-access article distributed under the terms of the Creative Commons Attribution License, which permits unrestricted use, distribution, and reproduction in any medium, provided the original author and source are credited. 
relatives were informed how to clean and dress the wounds and how to exercise their knees and hips.

The patients were followed regularly at one month intervals. Anteroposterior and lateral $\mathrm{x}$-rays were obtained. Fracture union, malunion, non-union, angulation, shortening, and implant failure (complications) were noted during follow-up. Varus malunion was defined as a $>10^{\circ}$ difference in the femoral neck-shaft angle between the fractured and uninvolved sides. Shortening malunion was defined as a $>2$-cm leg length discrepancy. Bipolar hemiarthroplasty was performed for hip revision if there were serious mechanical complications or nonunion.

\section{Results}

Twenty-six high risk (ASA 3-4) patients with intertrochanteric femur fractures were admitted to our clinic over a nearly 2 -year period. The average patient age was 85.5 (range 71-96) years and 16 patients (61.5\%) had right-side fractures. There were 12 males (46.1\%) and 14 females (53.9\%). According to the modified Evans classification, there were eight (30.8\%) stable and 18 (69.2\%) unstable fractures.

Patients with ASA grade 3 accounted for $23.1 \%$ of the study population (six patients) and their average age was 82.6 years. The remaining 20 patients were ASA grade 4 (76.9\%), and their average age was 86.3 years. All of the patients had at least one systemic disease that had to be stabilized preoperatively, including 14 in cardiac failure, 7 with prior myocardial infarctions, 3 with uncontrolled hypertension, and 2 with uncontrolled diabetes.

The average operating time was 27.1 (range 20-35) minutes and the median hospitalization was 7.8 days. The average time from fracture to operation was 2.4 days. The mean follow-up time was 24.4 months. Four (15.4\%) patients died during early post-operative period due to systemic diseases; three of them were female. All four patients who died were ASA grade 4 , so $20 \%$ of the ASA grade 4 patients died during follow-up ( 2 of them died during follow-up after revision surgery).

No complications occurred in 13 patients, 2 of them died during follow-up. Of the remaining 13 patients with complications during follow-up, $10(38 \%)$ had implant failure (6 patients with pin migration, 4 patients with pin cut-out) and $3(11.5 \%)$ had pin tract infections before union. Six ( 2 patients with pin migration, 4 patients with pin cutout) of the twenty-six patients $(23.1 \%)$ underwent revision surgery, and two of these died after the revision operation. There were no infections after revision (Figure 1).

Of the patients who had implant failure, $60 \%$ were underwent reoperation. The revision involved a bipolar hemiarthroplasty of the hip. Of the revision patients with pin migration, one of them died after the re-operation. The remaining four implant failure patients, who did not have revision, had delayed union resulting in shortening and varus
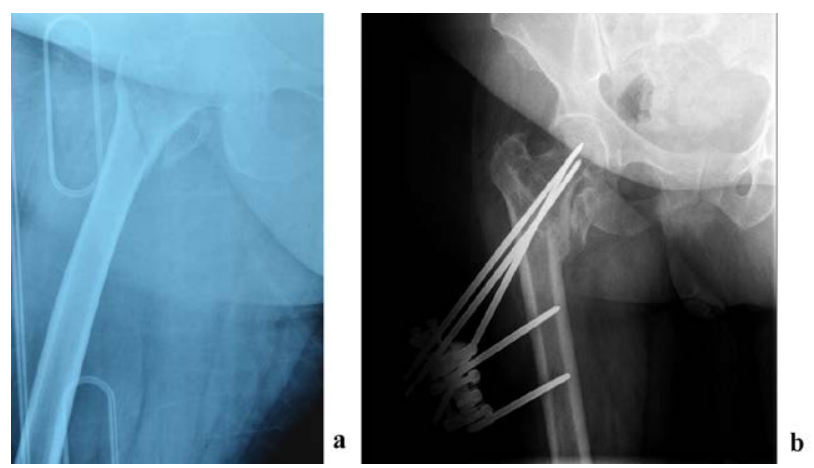

Figure 1: a) Preoperative x-ray of a patient in the no-complication group. b) $X$-ray of the same patient at 14 weeks shows union. malunion. Two of 3 patients with pin tract infections had varus malunion and shortening after union. Six patients had malunion (shortening and varus), comprising $46 \%$ of the patients with complications (Figure 2).

The patients with pin tract infections were treated with antibiotics, regular dressings, and periodic debridement. The external fixators were removed as soon as possible after union.

In the patients with no complications, the time to union was 13.4 weeks. The patients with complications (except dead and revised ones) achieved union after 17 weeks.

\section{Discussion}

Advancing technology and treatment modalities have increased the life expectancies of males and females, so the incidence of intertrochanteric femur fractures [1] has increased. Given the high mortality and morbidity rates of these fractures [11,12], especially in older people, there are concerns about surgical treatment options. Furthermore, osteoporosis causes mechanical complications such as shortening, collapse, and pin penetration, increasing the concerns about the stability of fixation methods. In our series, although we demonstrated the advantages of external fixation [6-8], such as shorter operating and hospitalization times, no need for blood transfusions, and earlier mobilization, there was a high complication rate in our highrisk patient group especially due to mechanical causes. Some patients with complications underwent revision using bipolar hemiarthroplasty, which increases the hospital stay and blood loss, impairs the biology due to open surgical trauma, and places excessive stress on the patients' general health. Increased costs are another important concern. Although external fixation is useful for reducing patient mortality and morbidity, the results of complications can cause more devastating situations.

Pin tract infection is an important complication because of the high postoperative incidence [13-15]. However, treatment is relatively easy, especially after pin removal. In our study, the pin tract infection rate
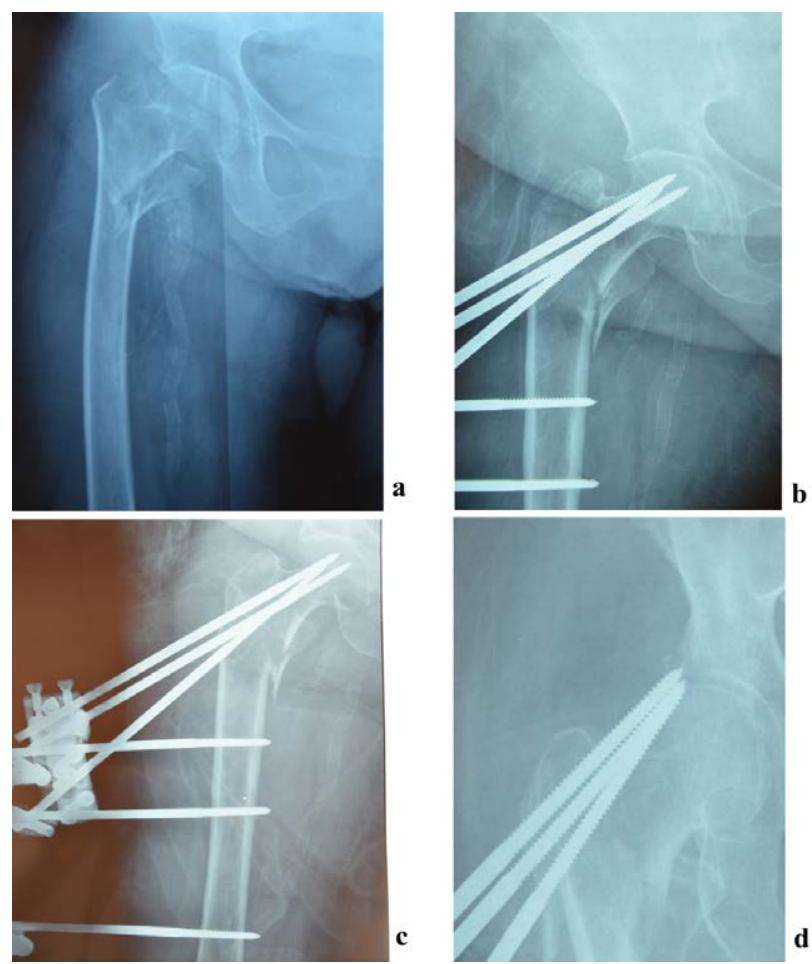

Figure 2: a) Preoperative $x$-ray of a patient in the complication group. b) The $x$-rays at $4^{\text {th }}$ week, c) The $x$-rays at $8^{\text {th }}$ week, d) The $x$-rays at $11^{\text {th }}$ week, There was pin migration and the hip was revised with a bipolar hemiarthroplasty. 
was moderate and the infections were treated easily with antibiotics, debridement, and pin removal. However, this caused some patient discomfort.

Some clinical studies emphasize the advantages and benefits of external fixation in high-risk older people with intertrochanteric femur fractures, especially with newer-design external fixators. The surgical technique is an important determinant of mechanical complications. With optimum technique and improved implant design $[7,14,16]$, mechanical complications can be reduced to a negligible level. Until that time, the golden standard treatments of pertrochanteric fractures should be DHS/DCS fixation systems or proximal femoral intramedullary nails. Because they have superior mechanical properties and less mechanical complications in compared to external fixation [17].

In conclusion, in light of our findings, we do not recommend using pertrochanteric external fixators in high-risk patients due to the high revision rate and mechanical complications. Well-designed prospective controlled studies with more subjects are needed to quantify the advantages and disadvantages of this technique.

\section{Conflict of interests}

Authors have no conflict of interests to disclose

\section{References}

1. Ozkaya U, ParmaksizoÄŸlu AS, GÃ¹/4l M, KabukÃ§uoÄŸlu Y, Ozkazanli G, et al. (2008) [Management of osteoporotic pertrochanteric fractures with external fixation in elderly patients]. Acta Orthop Traumatol Turc 42: 246-251.

2. Dempster DW (2011) Osteoporosis and the burden of osteoporosis-related fractures. Am J Manag Care 17 Suppl 6: S164-169.

3. Lane JM (2011) Osteoporosis and fracture risk. Orthopedics 34: 370.

4. Kazemian GH, Manafi AR, Najafi F, Najafi MA (2014) Treatment of intertrochanteric fractures in elderly highrisk patients: dynamic hip screw vs. external fixation. Injury 45: 568-572.

5. Petsatodis G, Maliogas G, Karikis J, Christodoulou AG, Venetsanakis G, et al (2011) External fixation for stable and unstable intertrochanteric fractures in patients older than 75 years of age: a prospective comparative study. J Orthop
Trauma.; 25: 218-223.

6. Baumgaertner MR (2002) The pertrochanteric external fixator reduced pain hospital stay, and mechanical complications in comparison with the sliding hip screw. J Bone Joint Surg Am 84-84A: 1488.

7. Moroni A, Faldini C, Pegreffi F, Hoang-Kim A, Vannini F, et al. (2005) Dynamic hip screw compared with external fixation for treatment of osteoporotic pertrochanteric fractures. A prospective, randomized study. J Bone Joint Surg Am 87: 753-759.

8. Vossinakis IC, Badras LS (2002) The external fixator compared with the sliding hip screw for pertrochanteric fractures of the femur. J Bone Joint Surg Br 84: 23-29.

9. Dripps RD. New classification of physical status. Anesthesiol. 1963;24: 111.

10. Saklad M. Grading of patients for surgical procedures. Anesthesiol. 1941;2: 281-4.

11. Clayer MT, Bauze RJ (1989) Morbidity and mortality following fractures of the femoral neck and trochanteric region: analysis of risk factors. J Trauma 29: 1673-1678.

12. Iolascon G, Gravina P, Luciano F, Palladino C, Gimigliano F (2013) Characteristics and circumstances of falls in hip fractures. Aging Clin Exp Res 25 Suppl 1: S133-135.

13. Devgan A, Sangwan SS (2002) External fixator in the management of trochanteric fractures in high risk geriatric patients--a friend to the elderly. Indian J Med Sci 56: 385-390.

14. Karn NK, Singh GK, Kumar P, Singh MP, Shrestha BP, et al. (2009) Management of trochanteric fractures of the femur with external fixation in highrisk patients. Int Orthop 33: 785-788.

15. Ozdemir H, Dabak TK, Urgüden M, Gür S (2003) A different treatment modality for trochanteric fractures of the femur in surgical high-risk patients: a clinical study of 44 patients with 21-month follow-up. Arch Orthop Trauma Surg 123: 538-543.

16. Vossinakis IC, Badras LS (2001) Management of pertrochanteric fractures in high-risk patients with an external fixation. Int Orthop 25: 219-222.

17. Moroni A, Faldini C, Pegreffi F, Giannini S (2004) HA-coated screws decrease the incidence of fixation failure in osteoporotic trochanteric fractures. Clin Orthop Relat Res: 87-92. 